\title{
Research on Green Construction Technology Applied Guangzhou Hongding Building Project
}

\author{
Yong Zhong LOU \\ School of Architecture \& Civil Engineering, Huizhou University, Huizhou, Guangdong 516007, China
}

\begin{abstract}
The green construction technology is the embodiment of sustainable development strategy in the construction industry, and it is a new construction mode which requires a higher environmental protection. Based on the Hongding building project, this paper describes the application and innovation of technical in the process of implementing green construction in the project, as well as the difficulties and characteristics in the specific practice; .The economic and social benefits of green construction are compared to the traditional construction model; . The achievements and experience of the green construction technology are summarized in the project; The ideas and methods in the process of implementing green construction are abstracted; some suggestions are put forward for the development of green construction.
\end{abstract}

\section{Background of Implementing Green Constructions}

With the fast development of Chinese urban construction scale, a large amount of materials and energy are consumed in the construction process. The current situation of the polluted environment goes against the concept of Energy-saving \& Low-carbon and Green \& Environmental-Friendliness currently promoted by China. Therefore, developing green construction technology becomes the urgent requirement for the current construction industry and the inevitable path for Chinese construction industry to achieve sustainable development [1]. Responding to the call of China and following the requirements of green construction's guidelines and assessment standards, Guangzhou Hongding Building Project actively constructs green construction sites, promotes the effective measures of "four conservancies and one environmental-protection" and achieves the aim of "low energy consumption, low pollution, recycled use of resources and the harmony between humans and the nature" on the precondition of guaranteeing constructions' quality, safety and schedule.

\section{Pre-phase Planning of Green Constructions}

\subsection{Green Construction Management System}

Guangzhou Hongding Building Project is to build one high-rise building complex. The architectural planning is: five floors for commercial use and 30 floors for flats, with an architectural area of 17,000 square meters and

* Corresponding author: Email: 58307085@qq.com overall construction area of 140,000 square meters. The building's structure form is frame-core tube structure.

To promote the green construction management comprehensively, it is necessary to set up a green construction leading team first, which is equipped with green construction departments and teams that assign different work to each personnel; Next, formulating regulations and systems to implement systematic guarantee, such as Green Construction Index Management System, Green Construction Assessment Responsibility System, Energy Use and Management System, Environmental Protection and Management System, Green Construction Assessment and Evaluation System [2].

\subsection{Construction Management}

The department should carry out dynamic management of the whole implementation process, manage and supervise each link from construction planning, material procurement, on-site construction and project acceptance.

It is advised to put up placards in the living zone and construction zone on the construction site, thereby creating the atmosphere of green constructions and enhance employees' awareness of green constructions.

\subsection{Assessment Management}

Together with proprietors and supervisors, the project department examines the implementation of green constructions every month, grades and assesses the implementation in accordance with GB/T50640-2010 in Construction Project Green Construction Assessment Standards to achieve sustainable improvement; .The green construction leading team randomly examines 
green constructions and comprehensively assesses the implementation of the project's green constructions until the project is accepted and delivered to proprietors for use [3].

\section{Measures of Green Constructions}

\subsection{Environmental Protection}

\subsubsection{Control of Dust Pollution}

It is necessary to carry out hardening and greening of the on-site construction's primary and secondary roads, the material processing zone, the office zone and the living zone in accordance with requirements. Meanwhile, pour water on the primary and secondary roads to reduce dust regularly.

Service-racks, dampness-absorbing cushion and high-pressure water guns are arranged at the entrance and exit, which ensure vehicles' sanitation and prevent vehicles' tires from bringing mud out of the construction site and making outside roads dirty.

It is advised to adopt measures to cover vehicles that may easily cause dust when delivering earthwork, concrete and other things. It is prohibited from overload to avoid spillage.

Under the weather with wind bigger than Level-4, carrying out earthwork refilling, transshipment and other construction operations that may cause dust pollution will not be allowed.

In the structure construction phase, premixed concrete and mortar will be adopted.

Professional examination unit regularly tests the TSP concentration in positions with the same height of the shield near the construction site and achieves constant dynamic supervision. The testing results all meet normal requirements.

\subsubsection{Control the Emission of Harmful Gases}

It is prohibited from burning various wastes on the construction site. And transportation vehicles must meet the local region's exhaust emission standards. Vehicles failing to meet standards are prevented from entering the construction site.

The welding of steel components is carried out by carbon dioxide gas protection welding and other welding techniques that produce fewer waste gases. The smoke emission of electrical welding should meet the regulations of national standard-Comprehensive Emission Standards for Atmospheric Pollutants.

\subsubsection{Control of Construction Wastes}

Steel bars, templates and other architectural materials are blanked by professional personnel that have rich experience, so as to avoid unnecessary rework that increases construction wastes; improve the qualities of templates' seams and the seams of steel bar truss steel plates, so as to avoid or reduce spillage.

The department should enhance the recycled and reuse management of construction wastes: Setting up closed waste separation station on the site and process construction wastes according to different categories; smash gravels, broken bricks, concrete and other basic root that are paved for temporary roads into gradations for refilling foundation pits; the recycling of steel bar truss plate's leftover materials is carried out by a professional company; the wood material and plats are cycled by plywood mill and paper mills; short steel bars are used to fix electrical switches and siding wall's position bars.

The dust bins can be divided into recycled use, non-recycled use and toxic \& harmful wastes, which are cleared and transported regularly.

Construction materials' packages are centrally piled before being uniformly recycled by manufacturers, and the rate of recycling packages reaches $100 \%$.

Printer's oil boxes, toner cartridges, cells and other toxic \& harmful wastes are recycled in closed box. Manufacturers adopt the service of exchanging old with new ones and recycled them for reuse.

\subsubsection{Control of water and land pollution}

The sewage should be directly discharged into the municipal sewage pipe network. It should be first discharged into the sedimentation tank. After undergoing twice sedimentation \& filtration of cement paste and mortar, it is used to spray on the hardened floor within the construction site to reduce dust or discharged into the municipal sewage pipeline.

The special sewage pipelines are arranged in the toilets and canteens in the living zone. Meanwhile, link them to the septic tank, oil separator and other facilities to process life sewage; set filtration webs in the sewage discharge pipelines of toilet and canteens, which are cleared by professional personnel regularly.

The site's sewage discharge entrusts qualified units to carry out sewage water quality testing regularly. The sewage discharge meets the requirements of GB20425-2006 in Sewage Discharge Comprehensive Standards.

The place for storing chemical products and other toxic materials has strict water-proof designing to prevent oil and liquid from leaking.

\subsubsection{Control of light pollution}

It is prohibited from using lightening equipment that has no cover and protection in the construction site. The lights for lightening at night are energy-conserving and have a set cover, with the lightening direction concentrated in the construction range to avoid influencing the common life of surrounding residents. And it should reasonably formulate construction operation plans and try to avoid have construction between 22:00 6:00 a.m. 
It is suggested adopting LED light in the basement of the construction site and for floor lightening. It is prohibited from using incandescent light bulbs. LED lights not only have good outcomes but also save electricity.

\subsubsection{Noise and Vibration Control}

The department should promote civilized constructions, enhance management of human noises and reduce humans' uproars. The schedule plan should be reasonably arranged and avoid construction operations that have huge noises at night, such as concrete pouring.

The mechanic equipment that produce strong noises should be kept away from the office zone and the living zone of the construction site, as well as surrounding living residential zones, so as to prevent the construction from disturbing residents.

The environmental-friendly and low-noise vibrators and other machines are used for constructions. When vibrating, it is prevented from contacting modules and steel bars to prevent the vibrator from running idly and avoid or reduce construction noises. These machines are maintained by professional personnel regularly.

Establishing noise supervision sites surrounding the construction site and arrange professional personnel for dynamic supervision.

\subsection{Measures of saving and utilizing materials}

The department implement quota material-picking, formulate and implement measures of controlling crucial points with targets, so as to improve the rate of saving materials. And the material procurement plan, time and sequence of entering the site reasonably should be formulate reasonably to reduce the stock and avoid overstock or waste.

The detachable and environmentally-friendly walls that can be used for many times are adopted; the protection parts of adjacent edges and holes should use canalized, tooled and standardized wall that is detachable and used in recycled ways. The results are shown in Fig 1 and Fig 2.

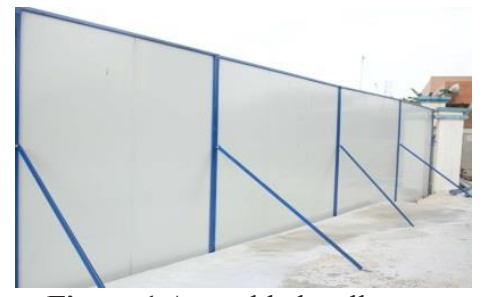

Figure 1 Assembled wall

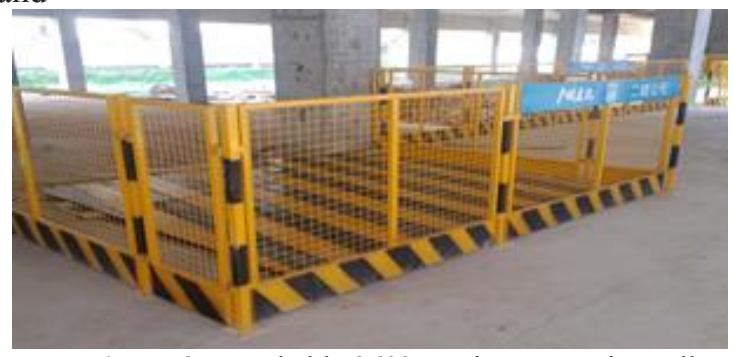

Figure 2 Detachable $360^{\circ}$-turning protection rail

(1) The concrete is maintained by covering straw bags and thin films;

(2) Cover the independent column concrete with plastic thin film for maintenance;

(3) Spray concrete maintenance protection liquid on the surface of walls to save water used for constructions.

\subsection{Measures of Saving Energy and Utilizing Energy}

The energy-conserving \& efficient electric appliance and construction equipment recommended by the country and industry are utilized; it is recommended to utilize invertor air-conditioners. On the site, utilize inverter high-voltage water pump to save energy. It is recommended to fully utilize renewable energy such as solar energy. Table of economic analysis before and after using energy-conserving equipment is shown in Table 1.

Table 1: Economic analysis before and after using energy-conserving equipment

\begin{tabular}{l|c|c|c|c}
\hline \multicolumn{1}{c|}{$\begin{array}{c}\text { Part of using energy } \\
\text { conserving equipment }\end{array}$} & $\begin{array}{c}\text { Electricity } \\
\text { before } \\
\text { using/month } \\
\text { (kilowatt) }\end{array}$ & $\begin{array}{c}\text { Electricity } \\
\text { before } \\
\text { using/month(kil } \\
\text { owatt) }\end{array}$ & $\begin{array}{c}\text { Saved electricity/month } \\
\text { (kilowatt) }\end{array}$ & $\begin{array}{c}\text { Saved electrical } \\
\text { fee/month } \\
\text { (yuan) }\end{array}$ \\
\hline $\begin{array}{l}54 \text { dormitories (use USB } \\
\text { socket and LED light) }\end{array}$ & 13,500 & 8,100 & 5,400 & 7,020 \\
\hline
\end{tabular}




\begin{tabular}{l|c|c|c|c}
\hline $\begin{array}{l}\text { Tower cranes (four LED } \\
\text { lights are used) }\end{array}$ & 1,920 & 480 & 1,440 & 1,872 \\
\hline $\begin{array}{l}\text { Human \&cargo elevator (use } \\
\text { frequency converting } \\
\text { equipment) }\end{array}$ & 3,010 & 1,600 & 1,410 & 1,833 \\
\hline $\begin{array}{l}\text { Construction elevator zone } \\
\text { use LED light belt) }\end{array}$ & 720 & 360 & 360 & 468 \\
\hline $\begin{array}{l}\text { Dormitory zone (use air } \\
\text { energy water heater) }\end{array}$ & 2,160 & 600 & 1,560 & 2,028 \\
\hline Sum & 21,310 & 11,140 & 10,170 & 13,221 \\
\hline
\end{tabular}

\subsection{Measures of Saving Land and Protecting Construction Land}

The on-site place is arranged reasonably and compactly. In the precondition of meeting the requirements on the environment, occupational health, security and civilized construction, the discarded place and blind corners are reduced. The construction on-site reduces the arrangement of temporary roads following the principle of combining permanent roads and temporary roads;

The construction plan of deep foundation pit is optimized, which reduces the earth excavation and refilling amount, reduces the disturbance to land to the largest extent and protects the surrounding natural and ecological environment.

The office zone and workers' living zone are two-floor assembled houses, which increase the rate of using land. The office zone and living zone are separated from the production zones and equipped with standard separation facilities.

\section{Conclusion}

In conclusion, this project has obtained significant economic benefits and social benefits by implementing green construction plans, which proves the green construction's feasibility and provides reference significance to promoting and implementing green construction projects in various regions in the future.

\section{Acknowledgments}

Supported by Huizhou Municipal Natural Science Foundation (No.2013B020015004)

\section{References}

1. Zhang Xiqian, Lin Lin, Wang Jun. The Present Situation and Prospect for Green Construction and Green Building. Construction Technology, 40:339 (2011), 1-7.

2. Ye Haowen, Zou Jun, Sun Hui, Yang Wei. The Key Green Construction Technologies of Guangzhou Zhoudafu Finance Center. Optimization of Capital
Construction, 44:10(2015), 28-32.

3. Zhu Jun, Zhang Haibin. Construction Management for Green Construction Demonstration Project. Construction Technology, 30:12(2015), 44-49. 